\title{
An Apple a Day: A Novel Way to Introduce Students to the Scientific Method
}

\author{
Debra Mauzy-Melitz and Oren Wellner \\ University of California-Irvine, Developmental and Cell Biology, Irvine CA 92697-2300 \\ USA \\ (dmauzyme@uci.edu; owellner@uci.edu)
}

\begin{abstract}
How does a scientist form a hypothesis? What are the important steps in the process? Can you change your hypothesis? These questions are not well understood by students. In this mini, we explored how a very simple hypothesis can be improved based on a pilot experiment and literature review. The activity started with the question "Does a red apple have more seeds than a green apple?" We progressed through the common steps used to design a hypothesis, test our initial hypothesis in a pilot experiment, compare our results to what is known in the literature and finally to modify our hypothesis. Along the way, the activity pointed out the importance of observational skills when collecting data as well as the importance of understanding the limitations of an experimental design. Participants determined how many seeds they have in a real apple. The results were discussed with respect to how the procedure might be modified and what equipment and skills facilitated the collection of the data. The group's results were then compared to another group's results (results from undergraduate courses). We then performed a simple background search to learn more about apple seeds and how seeds develop. We ended by modifying our hypothesis and determining the scientific merit of the new hypothesis compared the original question. The Seeds in an Apple activity has been tested in class sizes of 30 to 400 students, from 6th grade to juniors in college. The activity is appropriate for both science and non-science majors.
\end{abstract}

Keywords: hypothesis testing, experimental design, scientific method

\section{Mission, Review Process \& Disclaimer}

The Association for Biology Laboratory Education (ABLE) was founded in 1979 to promote information exchange among university and college educators actively concerned with teaching biology in a laboratory setting. The focus of ABLE is to improve the undergraduate biology laboratory experience by promoting the development and dissemination of interesting, innovative, and reliable laboratory exercises. For more information about ABLE, please visit http://www.ableweb.org/.

Advances in Biology Laboratory Education is the peer-reviewed publication of the conference of the Association for Biology Laboratory Education. Published articles and extended abstracts are evaluated and selected by a committee prior to presentation at the conference, peer-reviewed by participants at the conference, and edited by members of the ABLE Editorial Board. Published abstracts are evaluated and selected by a committee prior to presentation at the conference.

\section{Citing This Article}

Mauzy-Melitz D, Wellner O. 2020. An apple a day: a novel way to introduce students to the scientific method. Article $43 \mathrm{In}$ : McMahon K, editor. Advances in biology laboratory education, Volume 41. Publication of the 41st Conference of the Association for Biology Laboratory Education (ABLE). https://doi.org/10.37590/able.v41.abs43

Compilation (C) 2020 by the Association for Biology Laboratory Education, ISBN 1-890444-17-0. All rights reserved. No part of this publication may be reproduced, stored in a retrieval system, or transmitted, in any form or by any means, electronic, mechanical, photocopying, recording, or otherwise, without the prior written permission of the copyright owner.

ABLE strongly encourages individuals to use the exercises in this volume in their teaching program. If this exercise is used solely at one's own institution with no intent for profit, it is excluded from the preceding copyright restriction, unless otherwise noted on the copyright notice of the individual chapter in this volume. Proper credit to this publication must be included in your laboratory outline for each use; a sample citation is given above. 